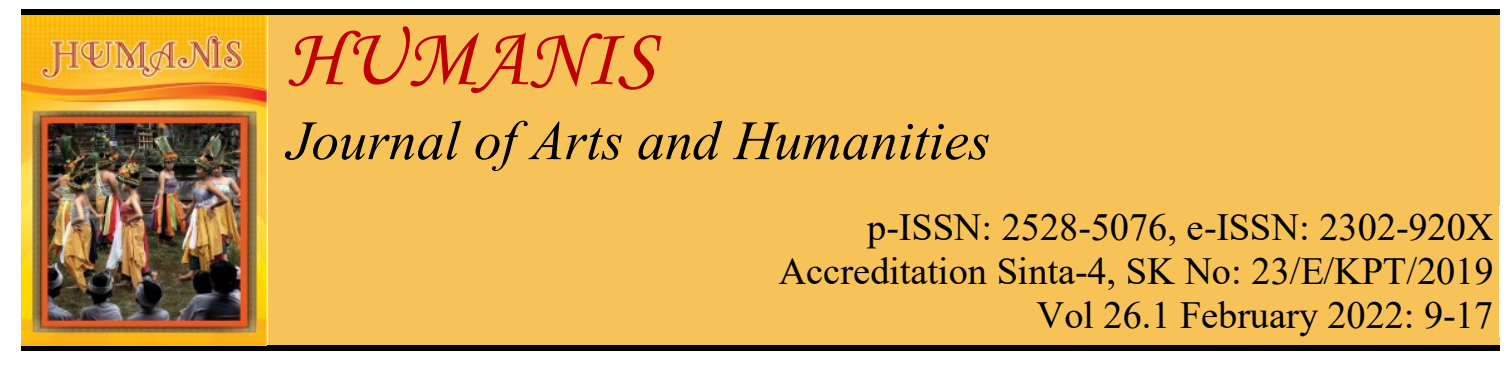

\title{
Female Main Character in Princess Mononoke Film: A Study of Ecological Feminism
}

\author{
Ni Putu Rhadani Sanjigandewi, Ni Ketut Alit Ida Setianingsih \\ Udayana University, Denpasar, Bali, Indonesia \\ Correspondence Email: puturhadani@gmail.com, alit_ida@yahoo.com
}

\begin{tabular}{|c|c|}
\hline Article Info & Abstract \\
\hline $\begin{array}{l}\text { Submitted: } 23^{\text {rd }} \text { July } 2021 \\
\text { Revised: } 20^{\text {th }} \text { August } 2021 \\
\text { Accepted: } 4^{\text {th }} \text { September } 2021 \\
\text { Keywords: feminism, ecological } \\
\text { feminism, women and nature } \\
\text { Corresponding Author: } \\
\text { Ni Putu Rhadani Sanjigandewi } \\
\text { email: puturhadani@gmail.com } \\
\text { DoI: } \\
\text { https://doi.org/10.24843/JH.202 } \\
\text { 2.v26.i01.p02 }\end{array}$ & $\begin{array}{l}\text { This study aims to analyses the female main character in } \\
\text { Princess Mononoke film that reflects ecological feminism. The } \\
\text { data of this study was taken from the Princess Mononoke film. } \\
\text { The data were analyzed by using the narrative-qualitative } \\
\text { method. Theory of women-other human Others-nature } \\
\text { interconnections by Karen J. Warren (2000) was applied to } \\
\text { find out the connection of the female main character with } \\
\text { nature. The results of this study show that the oppression of the } \\
\text { forest leads to the oppression of the female main character. } \\
\text { The forest was destroyed by humans, which lead to the } \\
\text { oppression of Princess Mononoke because she lost her family, } \\
\text { friend, and home. }\end{array}$ \\
\hline
\end{tabular}

\section{INTRODUCTION}

For over 200 years, women fought for their injustice in front of the world. There are many figures that echo the equality of women around the world who called themself feminists. Feminism is a conflict theory that suggests that power in society is divided based on gender and that patriarchal oppression of women exists in all sections of society in employment at home, education, and media (Gelling, 2020). Until the 1890s, the word "feminism" did not gain currency, although women were expressing the feminist view long before that. Through literary work and a discussion group, women expressed their voices. The concept of feminism is a movement that women demand equal rights with men. The rise of feminism happened because women are restricted to their rights and eventually spread to wide manifestations and variations (Hannam, 2013).

Ecological feminism was coined by Françoise d'Eaubonne, French woman suffrage, in 1974 (Tong, 2014). Ecological feminism is a branch of feminism that examines the oppression of the unjustified women, people of colour, children, and the poor with the unjustified domination of nature are connected (Warren, 2000). The unjustified domination of nature will also lead to the unjustified of women (Regan, 2020). Animalizing or naturalizing women in a (patriarchal) culture like animals is seen as inferior to humans, thereby reinforces and authorizes women's inferior status (Warren and 
Erkal, 1997, p. 12). Correspondingly with the feminization of nature with culture and women's inferiority with men. Everything that exists on Earth, including rational thought, is part of nature (Griffin, 2016, p. 10). The closer relationship may be caused by the awareness of one gender than another. Indian women have done a non-violent direct action to prevent deforestation caused by government-backed logging known as the Chipko Movement (Warren and Erkal, 1997, p. 5). Thus, this interesting topic is found in the Princess Mononoke film and shows the connection between women and nature. In this study, the writer used the theory proposed by Warren (2000) because the film used as the data source in this study can portray the ecological feminism that is related to the theory proposed by Warren.

\section{METHOD AND THEORY}

The primary data of this study was taken from the Princess Mononoke film (Animation, Fantasy), published in Japan on July 12, 1997, by Studio Ghibli house production. The film was directed and written by Hayao Miyazaki. The film is used because many aspects of the film reflect ecological feminism, such as movements, statements, and conversations (Dirgantari, 2020).

The process of collecting the data used qualitative audio materials. The method used is observation and documentation, furthermore, by watching the film and reading the film script that contains the data needed in the research. The technique used in collecting the data is by close reading and note-taking. Specifically, the writer used the following procedures; (1) Watching Princess Mononoke film completely, carefully, and understands it comprehensively, (2) Reading the film script carefully to provide a better understanding of the film, (3) Identifying and collecting the verbal and pictorial/visual data found in the film by giving the annotations and making notes about the information that indicates ecological feminism.

The collected verbal data were analyzed by using the narrativequalitative method through the following procedure; (1) identifying the ecological feminism by giving the annotations and making notes about the information that indicates ecological feminism both on verbal and visual data, (2) analyzing the ecological feminism based on the theory of ecological feminism proposed by Warren (2000), (3) concluding the analysis.

The study used the descriptive method in presenting the result of the analysis. The data have presented descriptively the relationship between the female main character of Princess Mononoke film with nature according to the ecological feminism theory.

Several previous kinds of research are related to this study to be used as references for this research.

Bhalla (2012) seeks to uncover the oppression experienced by the protagonist in Surfacing novel. She found that the protagonist underwent a situation where women were unconsciously oppressed by men and healed by the connection with nature. The research was conducted by a descriptive qualitative analysis method using the theory by Petra Kelly (1984).

Aji Septiaji et al. (2020) using the theory of transformative ecological feminism by Vandana Shiva (1997) to explore women's oppression in the short stories. There are several cases of oppression found, such as discrimination, natural exploitation, and gender stereotypes. The study used a descriptive qualitative analysis method to analyze the data.

Diastuti (2014) discovered the feminism issue that arises in the novel 
and analyzes the effects of feminism experienced by the character in the novel. The data were analyzed with the qualitative method. The result of the study shows there is gender inequality that is rooted in the system of inheritance only to men and the deficiency of the chance to self-actualization. The use of the theory of Modern Feminism proposed by Langermann \& Brantley (in Ritzer and Goodmann, 2004) points out that the inequality between men and women is socially constructed, and there is no basis for nature.

Kusuma (2015) focused on analyzing the intrinsic elements of the Story of an Hour film, especially in the main character, conflicts, and the extrinsic element on liberal feminism values by using Tong's framework. The qualitative descriptive method is used to analyze the data. Liberal feminism can be found in Louis Mallard's character when the conflicts started to appear in her life.

Andriyani (2017) focused on the intrinsic element in the film and used the theory proposed by Kenney (1996) and the analysis of the feminism issue reflected in the film with the theory proposed by Langermann and Brantly (in Ritzer and Goodmann, 2004). The qualitative method is used to analyze the data. The findings show that the main female character of the film depicted feminism and her struggle and journey in the process of healing herself through traveling and yoga practices.

The theory used to analyze the data is the theory of women-other human Others-nature interconnections proposed by Waren (2000). Ecological Feminism consists of two fundamental concepts, namely "ecology" and "feminism". Ecology means the "study of organisms in their environment' (Kitchin and Thrift, 2009). These two concepts then combine to become one. Thus, this combination which is called ecological feminism emphasizes how patriarchal society or male-centered in treating both women and nature (Miles, 2018). Ecological feminists claim there is an important connection between the unjustified domination of women and the unjustifiably dominated groups as "Others," both "human Others" and "earth Others" (Warren, 2000). Five features of an oppressive conceptual framework show roots of the unjustified dominations of women, nonhuman animals, and nature. Those include; (1) value-hierarchical, Up-Down thinking, (2) oppositional and mutually exclusive value dualisms, (3) power is conceived (and exercised) as "power-over" power, (4) creates, maintains, or perpetuates a conception and practice of privilege, (5) logic of domination (Warren, 2000). Trees, water, food creation, animals, poisons, and more commonly naturism (i.e., the unjustified domination of nonhuman nature) are feminist issues since understanding them encourages one to comprehend the interconnections among the domination of women and other subordinated groups of humans "other human Others", on the one hand, the domination of nonhuman nature, on the other hand, which called to be women-other human Others-nature interconnections (Warren, 2000). According to Warren, ten types of women-other human Others-nature interconnections tend to be discussed, but this study only used three types among them:

\section{Conceptual Interconnections}

The value of dualism, such as reason/emotion, $\mathrm{mind} /$ body, culture/nature, human/nature, and man/woman, is organized by the conceptual basis of structures of domination in the hierarchy that root set out the superior/inferior concepts. Conceptual frameworks are oppressive. One of the common features of an oppressive conceptual framework 
involves value-hierarchical thinking, that is, "Up-Down" thinking, which ascribes more prominent value to that which is higher, or on the other hand Up, than to that which is lower, or Down. It might be put men Up and women Down.

\section{Empirical Interconnections}

The ecological feminists offered the data that link women, children, people of colour, and the underclass with environmental destruction. Nature destruction indeed explains how the connection appeared. They explained many serious health problems contributed by the destruction of nature. The ignorance behaviour from the men as they make toxic and pollution were, they claim as the superior among nature. Indian women have done a non-violent direct action to prevent deforestation caused by government-backed logging where known as the Chipko Movement (Warren, 2015).

\section{Symbolic and Literary Interconnections \\ Ecological feminists have examined} the association of symbols and devaluation of women and nature in literature, art, theology, and religion. Ecological feminism is often presented as offering alternative spiritual symbols, such as Gaia as the Goddess symbol, where Gaia means Mother Earth (Sears, 2014). The focus arises between the symbolic connections between sexist and naturist languages such as inferiors' women and nonhuman nature by naturalizing women and feminizing nature. Furthermore, women are often described in animal terms, while nature is often described in female and sexual terms.

\section{RESULT \& DISCUSSION}

Ecological feminism examines the connection that the oppression of nature will lead to the oppression of women.
From this viewpoint, the analysis will be divided into two parts analysis, as follow:

\section{The oppression of nature:}

\section{Data 1}

Ape : We will not go. We will eat the human. Yes, let us eat the man creature.

San : Are you crazy? Just what happened to make the ape tribe change this way? Since when do apes eat the flesh of a man?

Ape : If we eat the human, we will steal his strength, and we will drive the other humans away. Give us the man creature.

San : Stop this. You know you can't possess the humans' strength by eating them. All that'll do is make you into something else, something even worse than human.

Ape : We plant trees. Humans tear them up. The forest does not come back. If we kill the humans, we will save the forest.

San : You mustn't give up. We'll find a way. The Forest Spirit is with us. Go on planting your trees and someday we'll beat them.

(Princess Mononoke: 00:56:17 - 00:57:04)

The ecological feminists offered the data that link women, children, people of colour, and the underclass with environmental destruction (Warren, 2000). The scene above shows humans blatantly cut the trees in the forest, which is the home of the inhabitants there. This resulted in anger for all the inhabitants in the forest, especially in this scene, the Ape Tribe. The forest area which the place of the Ape Tribe inhabitant was destroyed by humans. There was nothing left except the barren land without a single tree. Though they tried to plant trees again to bring back their home, it 
was useless because humans will cut the trees again and destroy their home yet again. Though they tried to plant trees again to bring back their home, it was useless because humans will cut the trees again and destroy their home yet again. This scene shows one of the oppressive conceptual frameworks which is power is conceived as "power-over" power (Warren, 2000). Furthermore, this also concerned San because she will lose another friend along with their home.

\section{Data 2}

Eboshi : Now watch closely, everyone. I'm going to show you how to kill a god, a god of life and death. The trick is not to fear him.

Ashitaka : No! Stop! Eboshi!

Eboshi : You will die!

Jigo : She did it! Quickly! Go get the head!

Eboshi : Quick, Jigo! Bring me that box of yours!

Jigo : The porters are all dead! Hurry! Hurry!

Eboshi : Be careful not to touch the spirit's body! It'll suck the life out of you! Here it is! One head, as promised!

(Princess Mononoke: 01:52:10 - 01:54:55)

Lady Eboshi is the chief of Iron Town. She was respected by all of her people. She has a big ambition to build a great town and weapon factory that will give benefits to all her people in Iron Town. Though all of her goals are good for her people, she has no respect for nature and tradition in her environment. To achieve her goals, she blindly cut the trees and burned the forest without any worries about the inhabitant of the forest and the balance of nature. She was not afraid of God or a sort of, especially the God in the Forest Spirit that takes the form of a deer. Thus, show the privilege of the human in keep the dominantsubordinate relationship. Lady Eboshi cooperated with Jigo to behead the God of Forest Spirit. It was a political demand from the Empire who was about to take over the woods. Thus, this shows one of the five features of the oppressive conceptual framework, which is, logic of domination. Where this feature point that subordination is a justified action. Lady Eboshi succeded in beheaded the God of the Forest Spirit. Lady Eboshi succeded in beheaded the God of the Forest Spirit. She was not afraid of her action. Lady Eboshi and Jigo both are greedy and do not bother with the consequences that they will face. God of the Forest Spirit is called to be the guardian of the Forest Spirit. The Forest Spirit is where all kinds of animals, trees, and spirits inhabit the forest. When the guardian of the forest was killed, then the forest will die, so the inhabitants living there.

From the scene above, it can be seen that nature is oppressed by humans because of human greed. The oppressive are conceptual frameworks. One of the common features of an oppressive conceptual framework involves valuehierarchical thinking, "Up-Down" thinking. (Warren, 2000). Furthermore, the value of dualism, which is human/nature, is organized by the conceptual basis of structures of domination in the hierarchy that root set out the superior/inferior concepts. The superiority of humans that they claim above nature, which both human Others and earth Others. In this case, Lady Eboshi has underestimated the power of nature and demands that nature and tradition are inferior things. She was above them and can do anything she wants to achieve her goal, even if it means destroying the forest and tradition in the area. It shows that Lady Eboshi carries out the dualism perspective. Where the higher value is held by 
humans, and the opposite is the lower value held by nature.

\section{The oppression of women:}

\section{Data 3}

$\begin{array}{lll}\text { Gonza } & : \text { She's down! We got } \\ & \text { her! } \\ \text { Eboshi } & : \text { Stay back. Cut off a } \\ & \text { wolf's head, and it still } \\ & \text { has the power to bite. } \\ \text { Gonza } & : \text { What? } \\ \text { Eboshi } & : \text { Take aim where she } \\ & \text { falls. Right. } \\ \text { Eboshi } & : \text { Open fire. } \\ \text { Warrior } & : \text { Yeah! } \\ \text { Ashitaka } & : \text { No! Stay back! } \\ \text { (Town } & : \text { Oh! What the devil was } \\ \text { people) } & \text { that? } \\ \text { Ashitaka } & : \text { Wake up. No! } \\ \text { (Town } & : \text { Skin her! } \\ \text { people) } & \\ \text { (Town } & : \text { Kill her, milady! Kill } \\ \text { people) } & & \text { her! } \\ \end{array}$

(Princess Mononoke: 00:48:31 - 00:49:52)

The oppression of women can be seen from this scene when San is harmed by people from Iron Town. Furthermore, this action shows the empirical connection. San lived in the forest, and the forest was destroyed by Lady Eboshi, and this anger all of the forest inhabitants because they lost their home. To stop Lady Eboshi's action, San as the daughter of the wolf-spirit, tries to fight humans and protect the forest. She comes to Iron Town to kill Lady Eboshi by herself. Unfortunately, Lady Eboshi and the people of Iron Town were prepared for the necessary action to back her down. With help from her warriors, Lady Eboshi shoots San with many canons. Lady Eboshi and the people of Iron Town trapped San then does a battle with San, but it was interrupted by Ashitaka. Thus, San got a little hurt from the attack of Iron Town. This whole action from the people of Iron Town hurt San root from their thinking that they hold the higher position from San. Thus, San is from the forest, and they are humans from the Town, which leads to the mindset that she is just merely a spirit or an animal that can do nothing besides attack impulsively. This impulsive action means that she was no prepared to attack Iron Town, differently from Lady Eboshi, which uses strategy.

Furthermore, this shows the valuehierarchical thinking, which is, UpsDowns thinking (conceptual connection). Ups-Downs thinking shows the Ups position holds a higher value which is the Lady Eboshi and the people of Iron Town. Downs position holds a lower value which is San, along with the forest inhabitant. Specifically, this illustrates the Ups/Down position such as Human/Nature and Mind/Emotion.

One of the oppressive conceptual frameworks is conceived of "powerover" power (Warren, 2000). Ups hold power over Downs, which shows through the people of Iron Town over San. In this scene, San is present as a human, particularly a human girl. Despite knowing that the attacker from the wolfspirit tribe is 'a young lady', people from Iron Town do not bother themselves and continued to hurt her. Furthermore, they also feel that is a justified action because wolves attack people and the town. Although the wolves attacking the town are the result because their home was destroyed by humans. They lose their home where they can find food and shelter. Thus, this shows the logic of domination feature from the oppressive conceptual framework. This feature shows that the justification of superiority over subordination (Warren, 2000). Thus, the Iron Town people think that it is a justified action to keeping their goal.

The attack of Iron Town is led by San, to save her family, their home, and others inhabitants in the forest. San is the daughter of the wolf spirit, also known as 
Princess Mononoke. Princess Mononoke is called to be the spirit of ghouls, beasts, and ancient gods. This spiritual symbol offers an alternative that presents ecological feminism, as well found in Gaia as the Goddes symbol in Greek mythology, where Gaia means Mother Earth (Sears, 2014). The focus arises between the symbolic connections between the female main character and another character (animals) in the film. She is an heir, a princess, a daughter, which also has a responsibility to protect and save the forest from danger. She has the same duty as the God of the Forest Spirit. They have a similar position, to be the protector. To protect the forest from the oppression caused by humans. Princess Mononoke and the Gods of the Forest Spirit are symbolized as protectors. Mononoke means 'evil spirit' (Arce, 2021). Thus this nickname was given by the people of Iron Town. Furthermore, 'San' was a literal name that means 'three' as she was taken as the third cub by Moro, the wolf-spirit leader. San is "neither human nor wolf" (Cavallaro, 2006). Additionally, as she was present as a spirit nor a human that appeared to be a mysterious and enigmatic force which is an unknowable thing (Harris, 2019).

People of Iron Town assume that the wolf stole a girl's soul, brainwashed her to make her kill Lady Eboshi as the leader of Iron Town. To bring back Princess Mononoke as a human again, they should clear the forest and kill the wolves. It pointed out the privileged feature from the oppressive conceptual framework. This feature shows that the Ups are gain an advantage over the Downs (Warren, 2000). Though, usually, the Downs are given a little privilege from the Ups. However, in this case, the forest and Princess Mononoke gain nothing.

San lost in her battle against the people from Iron Town. Therefore, it means she failed to save the forest. This failure leads to the destruction of the forest. Princess Mononoke forced her last remaining strength with the rest of the forest inhabitants, eventually lost the battle against the humans. Ultimately, as the forest was destroyed, she lost her family, friend and, home.

\section{CONCLUSION}

This film has a lot of aspects that can reflect ecological feminism. Princess Mononoke, as the female main character, shows this relationship clearly. The empirical connection shows that when the forest was destroyed, Princess Mononoke soon lost her family and home. The conceptual connection shows that the concept of superior/inferior shows in this film is human/nature, where the people of Iron Town with their leader and Princess Mononoke with the forest inhabitants. Princess Mononoke, as one of the spirits and the God of the Forest Spirit, is symbolized as the protector that protects the forest and other forest inhabitants from the oppression caused by humans. Thus, show how the connection between the oppression of the unjustifiable group "human Others" and the unjustifiable group "earth Others". The root of this connection appears when the forest, along with the inhabitant oppressed by humans. Eventually, Princess Mononoke was also oppressed as the forest was destroyed because she lost her family, friend, and home.

\section{REFERENCES}

Andriyani, P. G. (2017). Feminism Analysis in the Movie Eat Pray and Love by Elizabeth Gilbert. Udayana University Denpasar, Bali.

Arce, E. (2021). 'Mononoke' (in Princess Mononoke) - A Linguistic Note Linguaholic Blog. Retrieved on $11^{\text {th }}$ April 2021, from 
https://linguaholic.com/linguablog/ mononoke-meaning/

Ari Kusuma, P. (2015). Liberal Feminism Values in Kate Chopin's Story of an Hour. Dian Nuswantoro University, Semarang.

Bhalla, A. (2012). 'Ecofeminism in Margaret Atwood's Surfacing', International Journal of Scientific and Research Publications, Vol 2, No 10, 1-6.

Cavallaro, D. (2006). 'The Animé Art of Hayao Miyazaki', North Carolina: McFarland \& Company, Inc., Publishers.

Diastuti, N. M. (2014). Feminism Analysis in Austen's Novel Pride \& Prejudice. Udayana University, Denpasar, Bali.

Dirgantari, A. P. (2020). 'Ekofeminisme pada Tokoh San dalam film "Princess Mononoke" Karya Sutradara Hayao Miyazaki', PANTUN, Vol 5, No 1, 1-11

Gelling, C. (2020). Sociological Theory Feminism (Sociology Theory \& Methods) - YouTube. Retrieved on $10^{\text {th }} \quad$ November 2020, from https://www.youtube.com/watch?v $=$ D6Dl-9pSW-4\&feature $=$ youtu.be

Griffin, S. (2016). Woman and Nature: The Roaring Inside Her. New York: Open Road. Retrieved on 2th November 2020, from https://www.overdrive.com/search? $\mathrm{q}=$ BC348269-DB0B-4B52-996915D09F4039BE

Hannam, J. (2013). Feminism. London New York: Routledge (A Short History of a Big Idea).
Harris, W. (2019). 10 Facts about Princess Mononoke only Japanese Fans Will Know, ScreenRant. Retrieved on $11^{\text {th }}$ April 2021, from https://screenrant.com/factsprincess-mononoke-japanese-fanswill-know/

Kitchin, R. and Thrift, N. J. (2009). International Encyclopedia of Human Geography. First edition. Amsterdam: Elsevier.

Miles, K. (2018). Ecofeminism Sociology and Environmentalism, Encyclopedia Britannica. Retrieved on $21^{\text {th }}$ July 2021, from https://www.britannica.com/topic/e cofeminism

Regan, S. (2020). How Gender \& The Environment Are Intrinsically Linked, mindbodygreen. Retrieved on $21^{\text {th }}$ July 2021, from https://www.mindbodygreen.com/a rticles/ecofeminism-history-andprinciples

Sears, K. (2014). Mythology 101: from gods and goddesses to monsters and mortals, your guide to ancient mythology. Avon, Massachusetts: Adams Media.

Septiaji, A., Zuriyati, Z. and Rahmat, A. (2020). 'Women's Life in Indonesian Contemporary Short Stories: A Study of Ecofeminism Transformative', Indonesian Language Education and Literature, Vol 5, No 2,185-197.

Tong, R. (2014). Feminist Thought: A More Comprehensive Introduction. Fourth Edition. Boulder: Westview Press.

Warren, K. (2000). Ecofeminist Philosophy: A Western Perspective on What It Is and Why It Matters. 
Lanham, Md: Rowman \& Littlefield (Studies in social, political, and legal philosophy).

Warren, K. and Erkal, N. (1997). Ecofeminism: Women, Culture, Nature. Bloomington: Indiana University Press.

Warren, K. J. (2015). Feminist Environmental Philosophy, Metaphysics Research Lab: Stanford University. Retrived on $21^{\text {th }} \quad$ July 2021, from https://plato.stanford.edu/archives/s um2015/entries/feminismenvironmental/ 